SHS Web of Conferences 12, 01010 (2014)

DOI: $10.1051 /$ shsconf $/ 20141201010$

(C) Owned by the authors, published by EDP Sciences, 2014

\title{
Community-Based Rural Tourism: A Proposed Sustainability Framework
}

\author{
Kalsom Kayat ${ }^{1}$ \\ ${ }^{1}$ School of Tourism, Hospitality and Environmental Management, Universiti Utara Malaysia, 06010 \\ Sintok, Kedah, Malaysia
}

\begin{abstract}
Many tourism projects run by community in the rural areas are labelled as Community-based Rural Tourism (CBRT), a type of a more 'responsible' tourism that contributes to sustainable development. However, a framework is needed to enable planners and managers to understand its criteria thus ensuring that the CBRTs fulfil the sustainability requirement. This paper presents findings from a literature review on previous writings in this topic. Findings from an analysis on the criteria of a sustainable CBRT product are discussed. It is found that in order for it to play a role in sustainable development, a CBRT product must focus on competitive management, resource conservation, and benefit creation to the community. The three elements need to be supported, in turn, by community involvement and commitment. As the proposed conceptual framework of sustainable CBRT product can be a basis for further research in CBRT, it offers producing theoretical and practical implications.
\end{abstract}

\section{Introduction}

Community-based Rural Tourism (CBRT) is an extension of Community-based Tourism (CBT) that takes place in a rural setting. As in other CBTs, CBRT requires the involvement and participation of community in managing the tourism activities within their community which at the end contribues to their well-being and indirectly promotes their culture to the world. CBRT aims to extend the benefits from tourism activities to the community in the rural areas in return for their participation in the process of development as well as during the sales and delivery of the products and services [1]. Research from previous studies [2-3] have listed down several CBRT characteristics and involvement of the community and their participation in the activities plan are agreed to be the most important characteristics of CBRT. In other words, the project must be owned, managed and organized by the community itself so that the collective benefits gained from the programme will be enjoyed by the members of the community. The other important characteristic of CBRT programme is that it should aim to allow the visitors to experience the lifestyle of the community as a way for them to learn about the hosts' traditional culture.

Indeed, the significance of CBRT is anchored in its potential to change and upgrade the lives of those in the community through the tourism activities. It opens a window of opportunities for the local communities to strengthen their economic status, and in some cases, may lead to poverty reduction. In addition, CBRT programmes may become a source of empowerment especially among the youth and women. However, although rural tourism can become a tool towards sustainable development, it can also be a source of conflict and can potentially harm the environment as well as 
create adverse impacts on local communities [4-5] which can be avoided if it is carefully planned and developed.

How can the sustainability of a CBRT product be ensured? What criteria must it fulfill for it to be categorized as a sustainable programme? This paper analyzes the criteria of a sustainable CBRT product from information extracted and analyzed from previous research and proposes a conceptual framework of sustainable CBRT product that bears theoretical and practical.

\section{Literature Review}

\subsection{Sustainable Tourism, Sustainability and Rural Tourism}

Pakshir and Nair [6] gave a very comprehensive connotation of sustainable tourism and its attributes. According to them, sustainable tourism involves development with manners and scales that remain viable over an indefinite time period while ensuring that the development does not cause degradation or modification of the present environment. The list of attributes for sustainable tourism includes offering product that has durable quality, using the alternative energy sources as to preserve the nature and ecological balance, safeguarding national heritage, and sponsoring responsive and value-based tourism product. Earlier, Rozemeijer (2001) (in [7]) suggested that sustainable tourism must address its four dimensions namely economic viability, ecological sustainability, equitable distribution of the costs and benefits among the participants and transparency in its organization. While in the case of the Malaysian Homestay Programme, a home-grown CBRT product [8], three critical components related to sustainable development are highlighted by Ibrahim and Abdul Razzaq [9]. The programme consists of the product (the unique attraction offered by the programme), the participants (visitors) and the principal (hosts) and its initiatives to improve the economy of the rural community. Sustainable tourism put a particular focus on the delivery of the high quality products and services along with the preservation of resources related to them including the natural and heritage resources.

Three main pillars support the achievement of sustainable tourism goals. Each of the pillars has their own roles in ensuring the sustainability of a rural tourism product. In the social aspect, CBRT's sustainability comes from its role in empowering the local community and strengthening their social fabric as well as in educating visitors about local culture. Economically, CBRT helps improve the local community livelihoods through the financial and non-financial benefits from the tourism activities. Last but not least, its focus on the environment and cultural preservation ensures the sustainability of CBRT.

Maria Ana Borges who is the Project Officer of International Union for Conservation of Nature stated in her slide presentation titled "Integrating Business Skills into Ecotourism Operations: Ensuring Sustainability" that a suitable balance must be established between the pillars mentioned above as well as in the management and community's involvement [10] as to guarantee its long term sustainability. Sustainable tourism development is the only approach that emphasizes on interactions between the needs of visitor, industry, community and environment as well as involvement of all relevant stakeholders in addition to the political leadership [11]. Lastly, it is erroneous to discredit the importance of profit in CBRT. Sound financial performance is necessary for CBRT programmes to sustain as financial resources is needed to support the pillars of sustainable development mentioned above. However, profit maximization needs to be balanced with social empowerment as well as resource conservation in order for the programme to be sustainable.

\subsection{Criteria of Sustainable CBRT}

In supporting the main pillars of sustainable tourism, several components have been found to be the criteria of a sustainable CBRT product. These components can be clustered into five dimensions namely community involvement, empowerment and leadership; benefit to community; collaboration and networking; marketing and promotion; and conservation. 


\subsubsection{Community Involvement, Empowerment and Leadership}

Members of the community as a group is the main actor in a CBRT product as the existence of the tourism activities is often initiated by a group of people willing to be involved and participate in the process and operation of rural tourism activities in their community. Firstly, prior to the setting up of a CBRT product/programme in a rural area, community capacity building must be executed to ensure they have enough understanding, capability and motivation to develop a CBRT product with sustainability in mind [12]. In the case of the Malaysian Homestay Programme, regular trainings are given to the homestay operators and local community to guarantee that the tourism activities are managed well. This is in accord with Bhuiyan suggestion that CBRT operators need to be trained and guided on how the process of a CBRT product operates until they can manage their programme well independently [13]. The training process and initiatives are usually organized by the Government or the Non-Government Organization (NGOs) which are closely related to the environmental conservation. For instance, most operators of the Homestay programme in Malaysia who are registered under the Ministry of Tourism and Culture of Malaysia are trained by the government. However, there are a few homestay programmes which are trained by NGOs such as the Misowalai Homestay in Sabah.

In addition, leadership and the commitment to achieve the goals of the CBRT is one of the critical factors for a CBRT product as it needs the full commitment from the programme leader or coordinator as well as from the local community involved [14]. Yusnita, Amin and Muda [15] argued that the leader should apply the appropriate leadership style so that the followers can be more motivated and inspired to be involved and participate in the tourism activities. On the other hand, organizational management and commitment is crucial as the CBRT success depends on the organization of the programme [16].

Along with the above criteria, community member's direct involvement in any tourism development project can empower the community economically, socially and politically [17]. In addition, active involvement and participation of residents in the tourism development process seem to be prerequisites for achieving the goal of sustainability and thereby improving the overall welfare in the community [18]. In order to make a CBRT project sustains, community involvement needs to take place. CBRT requires commitment from a wide range of stakeholders including from the government and public sector as well as from the community [19]. Hence, all parties involved in this programme have to become participatory, responsive, and transparent in order to ensure the sustainability of CBRT product. Last but not least, the local community should learn to not solely be dependent on the assistance and financial support from the government or NGOs especially in terms of promotion and marketing [20].

\subsubsection{Benefit to the Community}

A CBRT project is sustainable as long as it produces net positive benefit to the community. In general, the aim for rural tourism development is to improve the community's level of economic, social and environment [21-22]. Examples of benefit includes the creation of community resources such as health services, education and infrastructure for the community itself . In addition, CBRT must benefit all stakeholders involved for it to last. The benefit enjoyed by the local community usually comes in the form of financial and non-financial. Subsequently, rural tourism could actually increase the opportunities for social contact and exchange among the local community with the visitors. In addition, rural tourism benefit the community as it focuses on the protection and preservation of local nature and heritage [23].

\subsubsection{Collaboration and Networking}

In order for the CBRT to attract create and sustain the demands for their programme, it must establish collaboration and networking with all relevant players in tourism industry. Collaboration is also 
critical for the CBRT to get the support they need to enhance their resources and facilities the CBRT product [24]. The local community could only become active participants if they have support from the government, private sector and NGOs to enable the skills and knowledge transferred to them [25]. In addition, Salazar [26] in his study stresses the key importance of the local tour guides in a CBRT product as he argues that communicative power in representing and interpreting the cultural heritage would have direct and potentially significant influences to the visitors. Thus, he concluded that a CBRT needs to be supported by tour guides either from outside of the community or from the community itself. On the other hand, specific training programmes focusing on skill development, business planning and marketing specific to the needs of entrepreneurs, products and tourism committee may need to be facilitated by external trainers who are engaged or connected through networking [27].

\subsubsection{Marketing}

Efficient marketing strategy needs to be implemented by the CBRTs to enable them to create awareness about their offerings to their potential visitors as well as to expedite the visitors in making the decisions to visit them thus sustaining their business operation. A study by Jamal, Othman and Nik Muhammad [28] suggested that CBRT marketers should pay attention to the functional, emotional and experiential elements of the product so as to better develop the positioning strategies and promotion of the CBRT product. On the other hand, this niche tourism should be marketed with the venturesegment in mind with the venture visitors as their target segment. This could be done through the advertising and promotional opportunities available online, in tourism-related magazines, and at the state travel information offices where most tourists tend to obtain travel-related information.

\subsubsection{Conservation}

Visitors come for the uniqueness of experience, so it is crucial to have the conservation of the community natural resources. Conservation of community resources needs to be one of the main characteristic of sustainable tourism development [29]. Conservation in this subject area refers to the preservation of the culture of a local community, the heritage in the area, the environment and nature that represents the identity of the tourism place. However, many view this type of tourism as bringing more harm than good in environmental aspect as it has the ability to dilute cultural values, initiate uniformity and produce negative impact on the traditional way of life [30]. In order to preserve all the community resources mentioned above, all the parties must have the awareness and efforts of conservation.

\section{Proposed Conceptual Framework}

A conceptual framework of sustainable community-based rural tourism (Figure 1) is proposed based on what is known about it so far. Any initiative in developing community-based rural tourism must be managed by focusing on three main objectives namely competitiveness, resource conservation and community involvement. Competitiveness is crucial to ascertain that the initiative is able to operate with profit in order to enhance the community's in terms of their socio-economic conditions. Resource conservation is also important as it is the basis for the project attractiveness as well as it important for the well-being of the community members and their future generation. Lastly, this type of tourism requires community involvement in every stage of its development. They need to be empowered in order to be involved, and the outcomes from the development must empower them even more. These objectives put the members of the community as the main focus of the development. 


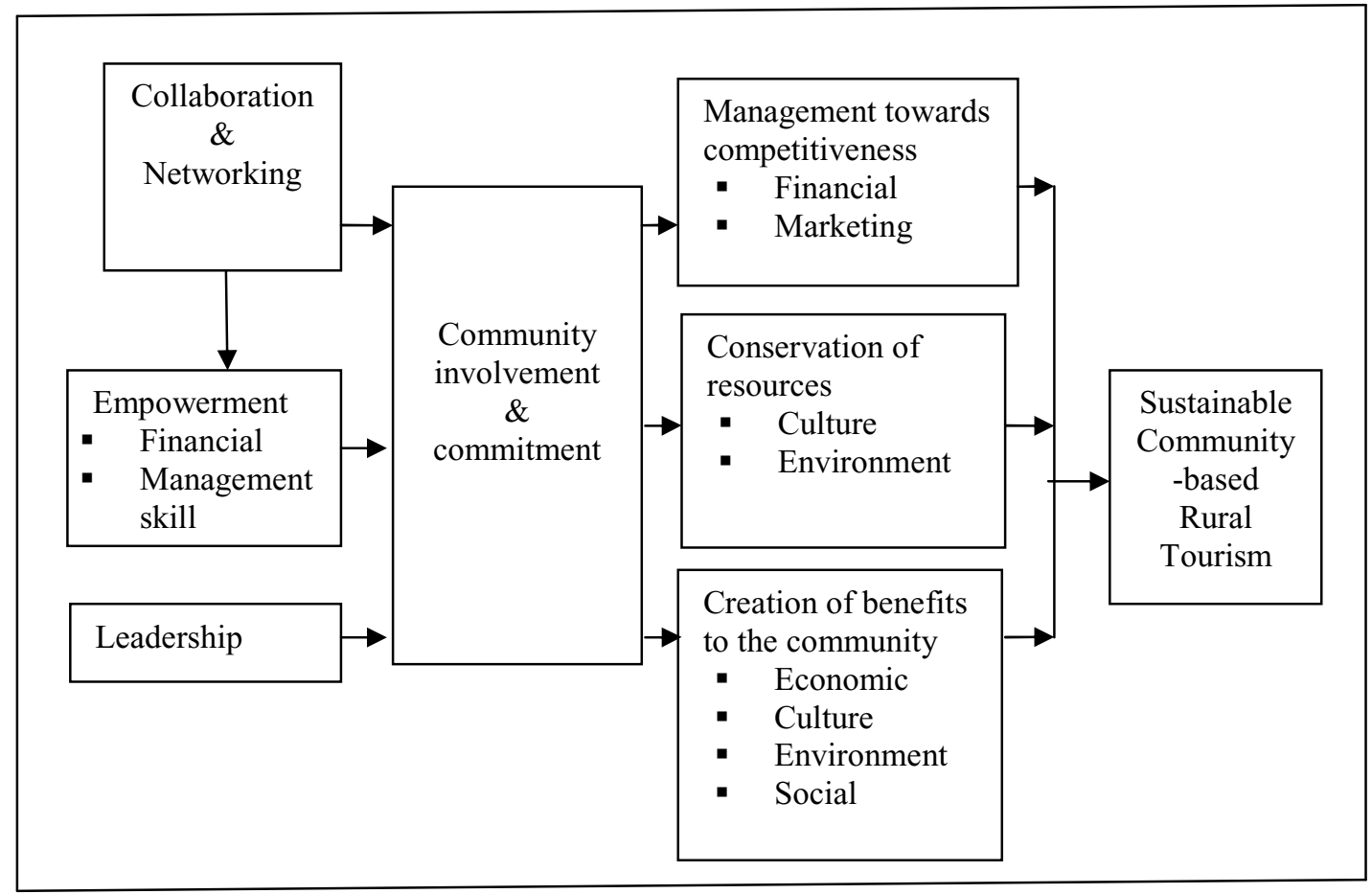

Figure 1. A Framework to Understand Sustainability of CBRT

This conceptual framework illuminates the criteria of a sustainable community based rural tourism which is derived from the pillars of sustainable tourism product. The community is the center of any community-based tourism and has been discussed widely in tourism studies namely in the aspects of organizational management, community participation, institutional environment, leadership, capacity and ability, and independence. The components are clustered together because they are closely related to the attitude or behavior of the local community in handling the tourism activities in their place. The community needs to be supported through collaboration and networking, empowerment and leadership to allow them to be a more able player in the development i.e. to be able to manage, conserve, and to create benefits to themselves and others in the community. Thus, in order for it to play a role in sustainable development, a CBRT product must focus on competitive management, resource conservation, and benefit creation to the community.

\section{Theoretical and Practical Implications of the Proposed Framework}

The proposed conceptual framework has both theoretical and practical implications. The framework can be used as a guideline to create instruments to be used in measuring the sustainability of a rural tourism product. It also allows for the testing of the relationships between variables which will then extends the current understanding in sustainable tourism part. For the practical implication, this framework can be a guide for policymakers and planners that are responsible for the development of rural tourism as it will ensure that the benefits from the development can be maximized.

This paper identifies the criteria of a sustainable CBRT product through a conceptual study. As studies on determining the criteria or the components that lead to the sustainable CBRT product are still limited, this framework could be adopted for that purpose. Although this study is conceptual in nature, the framework proposed has strong literatures support. To this extent, the study makes an important contribution to the present body knowledge in rural tourism area. However, the researcher 
would suggest that further studies to be carried out to test the applicability of this proposed framework in determining the sustainability of a CBRT product.

\section{Acknowledgement}

The funding for this project is made possible through the research grant obtained from the Ministry of Higher Education, Malaysia under the Long Term Research Grant Scheme 2011 [LRGS grant no: JPT.S (BPKI)2000/09/01/015Jld.4(67)].

\section{References}

1. R. Okech, M. Haghiri, B.P. George, Rural tourism as a sustainable development alternative: An analysis with special reference to Luanda, Kenya, Special Issue: Sustainability, Tourism \& Environment in the Shift of a Millenium: A Peripheral View, 6, 3, 36-54 (2012)

2. H. Goodwin, R. Santilli, Community-Based Tourism : a success? ICRT Occasional Paper 11, 137 (2009)

3. A.R. Abdul Razzaq, M.Z. Mustafa, A. Suradin, R. Hassan, Community Capacity Building for Sustainable Tourism Development, Business and Management Review, 2, 5, 10-19 (2012)

4. M. Cawley, D.A. Gillmore Integrated rural tourism: Concepts and practice, Annals of Tourism Research, 35, 2, 316-337 (2008)

5. B. Ertuna, G. Kirbas, Local community involvement in rural tourism development: The case of Kastamonu, Turkey, Revista de Turismo Patrimonio Cultural, 10, 2, 17-24 (2012)

6. L. Pakshir, V. Nair, Sustainability of homestay as a form of Community-based tourism (CBT): A case study of the rural community in Bavanat-Iran. TEAM Journal of Hospitality and Tourism, $\mathbf{8}$, 1, 5-18 (2011)

7. N.B. Salazar, Community-based cultural tourism: issues, threats and opportunities. Journal of Sustainable Tourism, 20, 1, 37-4 (2012)

8. R. Hussin, V. Kunjuraman, Sustainable community-based tourism (CBT) through homestay programmed in Sabah, East Malaysia. In Proceeding of the Social Sciences Research ICSSR 2014, 41-61 (2014)

9. Y. Ibrahim, A.R. Abdul Razzaq, Homestay Program and Rural Community Development in Malaysia, 7-24 (2010)

10. R. Hussin, V. Kunjuraman, 2014.

11. United Nations Development Programme and World Tourism Organization (2004). Making Tourism More Sustainable. Madrid, WTO.

12. Abdul Razzaq et al. (2012).

13. M.A.H. Bhuiyan, C. Siwar, S.M. Ismail, R. Islam, The Role of Home Stay for Ecotourism Development in East Coast Economic Region, American Journal of Applied Sciences, 8, 6, 540$546(2011)$

14. Abdul Razzaq et al. (2012).

15. Y. Yusnita, A. Amin, S. Muda, The Influences of Transformational Leadership in Homestay Programme, The Int. Journal of Social Sciences, 1, 1-7 (2012)

16. J.A. Ibrahim, M.Z. Ahmad. Program Homestay Pemangkin Pertumbuhan Ekonomi Luar Bandar, Kajian Kes: Negeri-Negeri Utara Semenanjung Malaysia. In Prosiding Perkem IV, 2, 227-242 (2009)

17. R. Hussin, V. Kunjuraman (2014).

18. B. Ertuna, G. Kirbas (2012).

19. G. Mansuri, V. Rao, Community-based and -driven development. World Bank Research Observer, 19, 1, $1-40$ (2004)

20. Abdul Razzaq et al (2012) 
21. L. S. Sebele, Community-based tourism ventures, benefits and challenges: Khama Rhino Sanctuary Trust, Central District, Botswana. Tourism Management, 31, 1, 136-146 (2010) doi:10.1016/j.tourman.2009.01.005

22. R. Okech, M. Haghiri, B.P. George, Rural tourism as a sustainable development alternative: An analysis with special reference to Luanda, Kenya, Special Issue: Sustainability, Tourism \& Environment in the Shift of a Millenium: A Peripheral View, 6, 3, 36-54 (2012)

23. R. Okech, M. Haghiri, B. P. George (2012)

24. M. Ghasemi, A. Hamzah, An Evaluation of the Role and Performance of NGOs in CommunityBased Ecotourism at Ulu Geroh, Gopeng, Malaysia. Monograph No. 9, (2011)

25. L.S. Sebele (2010)

26. Salazar, N.B., Community-based cultural tourism: issues, threats and opportunities, Journal of Sustainable Tourism, 20, 1, 37-41 (2012)

27. J. Braun, Community-based Tourism in Northern Honduras: Opportunities and Barriers. Unpublished Thesis. Department of Environment and Geography, University of Manitoba (2008).

28. S.A. Jamal, N. Othman, N.M.N. Muhammad, The Moderating Influence of Psychographics in Homestay Tourism in Malaysia, Journal of Travel \& Tourism Marketing, 28, 1, 48-61 (2011) doi:10.1080/10548408.2011.535443

29. H. Goodwin, R. Santilli (2009).

30. L. Pakshir, V. Nair (2011). 